\title{
Contaminant Transport in Capped Deformable Partially Saturated Sediments
}

\author{
${ }^{\dagger}$ Faculty of Civil Engineering \\ and Mechanics \\ Jiangsu University \\ Zhenjiang 212013, China
}

H. Zhang ${ }^{\dagger}$, H. Yang ${ }^{\ddagger}$, and D.-S. Jeng ${ }^{\dagger \S *}$

\author{
${ }^{*}$ School of Engineering and \\ Mathematical Sciences \\ City University London \\ London EC1V 0HB, United Kingdom
}

${ }^{\S}$ Griffith School of Engineering Griffith University Gold Coast Campus Queensland 4222, Australia

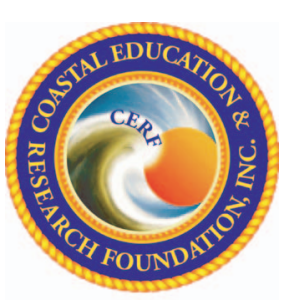

www.cerf-jcr.org

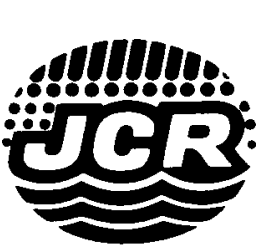

www.JCRonline.org

\section{ABSTRACT}

Zhang, H.; Yang, H., and Jeng, D.-S., 2015. Contaminant transport in capped deformable partially saturated sediments. Journal of Coastal Research, 31(6), 1489-1501. Coconut Creek (Florida), ISSN 0749-0208.

Contaminated sediment tends to consolidate in response to the loading imposed by an overlying cap layer. The form of transient solute advection through sediments and caps is consequently changed. Therefore, the contaminant discharge into the overlying water is expected to increase and the effectiveness of the in situ capping system will be strongly affected. In this study, a one-dimensional sediment-cap model coupling consolidation and advection-dispersion equation was established. A simplified model was proposed through the sensitivity analysis, and then a parametric study was conducted. Numerical examples concluded that the absorption, degree of sediment saturation, cap thickness, and sediment depth significantly affect the contaminant discharge from the top of the cap. Therefore, these parameters should be considered carefully during cap design.

ADDITIONAL INDEX WORDS: Sediment-cap model, consolidation, advection-dispersion equation, contaminant discharge.

\section{INTRODUCTION}

It is well known that increasing human activities significantly affect the marine environment by accelerating sedimentation rates and introducing contamination. In general, contaminants in coastal areas are generated by various sources, such as effluent discharge, storm-water runoff, and accidental leakages and releases. Natural tendency and the lower current velocity in bays and estuaries induce contaminants that are prone to being transferred long distances from the watershed upstream by dissolving in flows or by attaching to suspended solid particles (soil and organic materials) so that they become concentrated as sediments are deposited (Senten and Charlier, 1991).

The role of polluted subaqueous sediment on the quality of marine environment has drawn increasing attention. Based on coastal sediment cores in the Gegean Sea, Greece, Aloupi and Angelidis (2001) found that harbor sediment was constantly treated as the final deposition place of effluent-born pollutants in response to the discharge of untreated urban effluents into the ocean. Massoudieh, Bombardelli, and Ginn (2010) mathematically evaluated contaminant transport and transformation in sediment and water phases, considering the effect of both biotic and abiotic reactions on contaminant fate and mobility. The results indicated that because a variety of contaminants possessed a strong affinity to solid particles, the submarine deposits were characterized as a repository of pollution, i.e. a long-term source of pollution into the water column.

DOI: 10.2112/JCOASTRES-D-14-00039.1 received 3 February 2014; accepted in revision 10 May 2014; corrected proofs received 25 June 2014; published pre-print online 13 August 2014.

*Corresponding author: d.jeng@griffith.edu.au

${ }^{\circledR}$ Coastal Education and Research Foundation, Inc. 2015
Two main remediation approaches have been used for contaminated subaqueous sediments, i.e. dredging and capping. Dredging is normally defined as an excavation activity to subaquatic sediment for onshore treatment or storage in which some remediation technologies (such as incorporating activated carbon and phytoremediation) are explored and applied. However, the storage and treatment of hazardous dredged deposits require long-term management and relatively high technical support. Based on a European Sediment Network report, around 100 and 200 million $\mathrm{m}^{3}$ of contaminated sediments are produced annually from European countries (Bert et al., 2009). Therefore, it is an unrealistic or infeasible strategy to deal with such a vast quantity of polluted deposits by merely applying dredging.

Alternatively, in situ capping is called a remediationisolation method that involves the placement of clean, sandy materials over polluted sediments (Arega and Hayter, 2008). Capping has been used for highly polluted subaquatic sediments in environments with low hydrodynamic energy to limit the migration of contaminants contained in deposits (Liu, Jay, and Ford, 2001). Because of the relatively cost-effectiveness and small environmental impact, barrier layers have been extensively used around the world to address the contamination of submarine sediments. Arega and Hayter (2008) investigated the migration of hazardous chemicals under consolidation in a confined aquatic disposal site in the Lower Duwamish Waterway, Seattle, Washington. However, the mechanism of contaminant transport through the capped sediments has not been fully understood because of geotechnical and hydrodynamic complexity. The consolidation-induced contaminant flux resulting from the overlying capping, which could significantly affect the effectiveness of capping system (Alshawabkeh, Rahbar, and Sheahan, 2005), has only been 


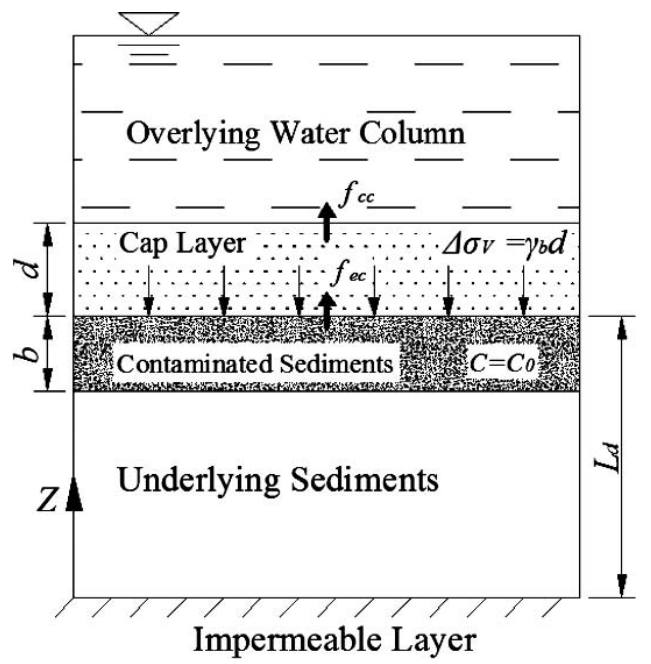

Figure 1. A schematic of a hypothetical contaminated sediment-and-cap system. The modeled domain consists of contaminated sediment and a sandy capping layer.

estimated numerically or experimentally by several researchers, with theoretical and equipment limitation.

The aim of this paper is to develop a new one-dimensional sediment-cap model to simulate the phenomenon of consolidation-induced contaminant transport through sediments and overlying cap layers. The influences of longitudinal dispersivity, self-weight of sediments, spatial variation of porosity, solid velocity (SV), and compressibility of pore water (CPW) on the contaminant fluxes are investigated in the parametric analysis.

\section{METHODS}

In this section, a hypothetical case for a capped contaminated seabed is proposed. Then, the governing equations and related boundary conditions for both the sediment and the capping layer are described. Following this, the simulation is performed using the finite element method.

\section{Problem Considered}

The present study focuses on the polluted seabed covered by a dredged material cap (typically constructed with a single layer of clean, high-permeability materials), which is analogous to the monographic study carried out previously by Alshawabkeh, Rahbar, and Sheahan (2005). The schematic of the example problem is depicted in Figure 1.

Because of the imposed buoyant weight of the capping layer or other externally applied loads, the subaqueous sediment undergoes consolidation accompanying the dissipation of excess pore pressure (assuming compression is positive). As shown in Figure 1, it is assumed that the capped sediment is of the large lateral extent described in a one-dimensional configuration. The vertical coordinate $z$ is taken upward from the impermeable bottom of sediment, and $L_{d}$ is the length of drainage path, which is equivalent to the sediment depth under the single drainage condition. The source of contaminants is assumed to be deposited with a uniform initial concentration $\left(c_{0}\right)$ in the contaminated layer (up to the depth $b$ below the sediment surface). Beyond this layer, the initial concentration is assumed to be zero. As for the initial stress distribution within sediments, the increase in stress of $\gamma_{b} d$ (where $\gamma_{b}$ is the buoyant unit weight of the cap material) is caused by the weight of cap materials with constant capping thickness $d$. The contaminant flux traveling from the sediment to the overlying cap is $f_{e c}$, and the contaminant flux from the cap into the overlying water column is represented by $f_{c c}$.

\section{Sediment Model}

The consolidation problem in the sediment layer caused by the overlying cap surcharge is solved by the basic equations that link the fluid velocity with excess pore pressure. The consolidation model is governed by one-dimensional unsaturated fluid storage derived by Zhang et al. (2012) and the Biot consolidation equation containing the self-weight term introduced by Tsai, Chang, and Huang (2006). They are, respectively,

$$
\begin{gathered}
S_{r} n_{0} \beta \frac{\partial p^{e}}{\partial t}+S_{r} \frac{\partial^{2} u}{\partial t \partial z}=\frac{1}{\rho_{w} g} \frac{\partial}{\partial z}\left(K \frac{\partial p^{e}}{\partial z}\right), \\
G \frac{2(1-v)}{1-2 v} \frac{\partial^{2} u}{\partial z^{2}}+\left(1-n_{0}\right)\left(\rho_{s}-\rho_{w}\right) g \frac{\partial u}{\partial z}=\frac{\partial p^{e}}{\partial z},
\end{gathered}
$$

where $p^{e}$ is the consolidation-induced excess pore pressure $\left(\mathrm{ML}^{-1} \mathrm{~T}^{-2}\right) ; u$ is the soil displacement in $z$ direction $(\mathrm{L}) ; S_{r}$ is the degree of saturation for sediments; $n_{0}$ represents the initial sediment porosity; $\beta$ is the compressibility of pore fluid $\left(\mathrm{T}^{2} \mathrm{LM}^{-1}\right) ; K$ denotes hydraulic conductivity $\left(\mathrm{LT}^{-1}\right) ; G$ is the shear modulus of sediments $\left(\mathrm{ML}^{-1} \mathrm{~T}^{-2}\right) ; v$ is Poisson's ratio; $\rho_{w}$ and $\rho_{s}$ denote the density of pore water and solid materials $\left(\mathrm{ML}^{-3}\right)$, respectively; and $g$ is the acceleration because of gravity $\left(\mathrm{LT}^{-2}\right)$. As Allison and Allison (2005) concluded, the maximum metal partitioning coefficient $K_{d}=10^{5} \mathrm{~L} / \mathrm{kg}$ leads to a negligible increase $(<0.6 \%)$ in the density of a solid because of the absorption. Therefore, it is reasonable to assume that $\rho_{s}$ is an independent variable to the solute mass concentration.

The compressibility of pore fluid $(\beta)$ defined by Fredlund and Rahardjo (1993) can be expressed with the degree of saturation, the volume of dissolved air within pore water, and absolute air pressure as follows:

$$
\beta=\frac{S_{r}}{K_{w 0}}+\frac{1-S_{r}+r_{h} S_{r}}{P_{a}+P_{0}}=\frac{S_{r}}{K_{w 0}}+\frac{1-S_{r}+r_{h} S_{r}}{\bar{P}_{a}},
$$

where $K_{w 0}$ is the bulk modulus of pore water $\left(\mathrm{ML}^{-1} \mathrm{~T}^{-2}\right)$, with $K_{w 0}=2.2 \mathrm{GPa}$ herein, and $r_{h}$ represents the volumetric fraction of dissolved air in pore water. The absolute air pressure $\bar{p}_{a}\left(\mathrm{ML}^{-1} \mathrm{~T}^{-2}\right)$ consists of the gauge air pressure $P_{a}\left(\mathrm{ML}^{-1} \mathrm{~T}^{-2}\right)$ and the atmosphere air pressure $P_{0}\left(\mathrm{ML}^{-1} \mathrm{~T}^{-2}\right)$.

Based on previous work (Peters and Smith, 2002), Zhang et al. (2012) further developed a one-dimensional transport equation that considered the effect of the degree of sediment saturation $\left(S_{r}\right)$, coefficient of fluid compressibility $(\beta)$, and constant longitudinal dispersivity $\left(\alpha_{L}\right)$. In this study, the Zhang et al. (2012) equation is adopted to describe the contaminant migration through deforming sediments with linear equilibrium controlled absorption, which can be characterized as 
Table 1. Summary of the parameter values for illustrative cases.

\begin{tabular}{|c|c|c|}
\hline & Case 1 & Case 2 \\
\hline \multicolumn{3}{|l|}{ Geometric characteristics } \\
\hline Contaminated sediment thickness $(b), \mathrm{m}$ & 0.25 & 0.25 \\
\hline Sediment thickness $\left(L_{d}\right), \mathrm{m}$ & 5 & 5 \\
\hline Cap thickness $(d), \mathrm{m}$ & 0.6 & 0.6 \\
\hline \multicolumn{3}{|l|}{ Sediment characteristics } \\
\hline $\begin{array}{l}\text { Reference solute mass concentration } \\
\quad\left(c_{o}\right), \mathrm{g} / \mathrm{m}^{3}\end{array}$ & 1 & 1 \\
\hline Sediment saturation $\left(S_{r}\right)$ & 1.0 & 0.8 \\
\hline Initial porosity of sediments $\left(n_{0}\right)$ & 0.5 & 0.4 \\
\hline Poisson's ratio (v) & 0.33 & 0.33 \\
\hline Hydraulic conductivity $(K), \mathrm{m} / \mathrm{s}$ & $1.0 \times 10^{-9}$ & $2.0 \times 10^{-9}$ \\
\hline Coefficient of consolidation $\left(c_{v}\right), \mathrm{m}^{2} / \mathrm{s}$ & $4.0 \times 10^{-7}$ & $4.0 \times 10^{-7}$ \\
\hline Shear modulus $(G), \mathrm{Pa}$ & $1.0 \times 10^{6}$ & $5.0 \times 10^{5}$ \\
\hline Gravity acceleration $(\mathrm{g}), \mathrm{m} / \mathrm{s}^{2}$ & 9.8 & 9.8 \\
\hline $\begin{array}{l}\text { Initial density of the pore fluid }\left(\rho_{w}\right) \text {, } \\
\mathrm{kg} / \mathrm{m}^{3}\end{array}$ & 1000 & 1000 \\
\hline Density of the solid phase $\left(\rho_{s}\right), \mathrm{kg} / \mathrm{m}^{3}$ & 2600 & 2600 \\
\hline Partitioning coefficient $\left(K_{d}\right)$ & 0 & 0 \\
\hline Effective diffusion coefficient $\left(D_{e}\right), \mathrm{m}^{2} / \mathrm{s}$ & $4.0 \times 10^{-10}$ & $3.0 \times 10^{-10}$ \\
\hline Longitudinal dispersivity $\left(\alpha_{L}\right), \mathrm{m}$ & 0.1 & 0.1 \\
\hline \multicolumn{3}{|l|}{ Cap characteristics } \\
\hline Density of cap materials $\left(\rho_{c}\right), \mathrm{kg} / \mathrm{m}^{3}$ & 2000 & 2000 \\
\hline Saturation of capping materials $\left(S_{r}^{c}\right)$ & 1 & 1 \\
\hline Porosity of capping materials $\left(n_{0}^{c}\right)$ & 0.25 & 0.25 \\
\hline $\begin{array}{l}\text { Effective diffusion coefficient of the } \\
\text { capping layer }\left(D_{e}^{c}\right), \mathrm{m}^{2} / \mathrm{s}\end{array}$ & $1.6 \times 10^{-10}$ & $1.6 \times 10^{-10}$ \\
\hline
\end{tabular}

$$
\begin{aligned}
{\left[S_{r} n_{0}\right.} & \left.+\left(1-n_{0}\right) \rho_{s} K_{d}\right] \frac{\partial c_{f}}{\partial t}=S_{r} n_{0} D_{e} \frac{\partial^{2} c_{f}}{\partial z^{2}}-\alpha_{L} \frac{K}{\rho_{w} g} \frac{\partial p^{e}}{\partial z} \frac{\partial^{2} c_{f}}{\partial z^{2}} \\
& +\frac{\partial c_{f}}{\partial z}\left\{-\alpha_{L} S_{r} n_{0} \beta \frac{\partial p^{e}}{\partial t}-\alpha_{L} S_{r} \frac{\partial^{2} u}{\partial z \partial t}+\frac{\alpha_{L} \beta K}{\rho_{w} g}\left(\frac{\partial p^{e}}{\partial z}\right)^{2}\right. \\
& \left.+S_{r} D_{e}\left(1-n_{0}\right) \frac{\partial^{2} u}{\partial z^{2}}+\frac{K}{\rho_{w} g} \frac{\partial p^{e}}{\partial z}-\left[S_{r} n_{0}+\left(1-n_{0}\right) \rho_{s} K_{d}\right] \frac{\partial u}{\partial t}\right\} \\
& +S_{r} n_{0} \beta \frac{\partial p^{e}}{\partial t} c_{f}-\beta \frac{K}{\rho_{w} g}\left(\frac{\partial p^{e}}{\partial z}\right)^{2} c_{f}+S_{r} n_{0} \beta \frac{\partial u}{\partial t} \frac{\partial p^{e}}{\partial z} c_{f}
\end{aligned}
$$

where $c_{f}$ denotes the solute contamination in the fluid phase of sediments $\left(\mathrm{ML}^{-3}\right)$ and $D_{e}$ represents the effective diffusion coefficient $\left(\mathrm{L}^{2} \mathrm{~T}^{-1}\right)$.

To solve the preceding governing equations, some appropriate boundary conditions are required. Because the impermeable rigid boundary is assigned to the sediment base $(z=0)$, there is no soil displacement in the $z$ direction and no vertical flow that indicates a zero gradient of excess pore pressure at the bottom of sediments over the computing time under the single drainage condition, i.e.

$$
\frac{\partial p^{e}(0, t)}{\partial z}=0, u(0, t)=0 .
$$

The Danckwerts boundary condition (Danckwerts, 1953) is adopted at the fixed impermeable boundary, where the gradient of solute concentration is assumed to be zero:

$$
\frac{\partial c_{f}(0, t)}{\partial z}=0
$$

At the sediment surface $\left(z=L_{d}\right)$, the excess pore pressure is assumed to have vanished because of free drainage. The effective normal stress along the sediment surface is assumed to be equivalent to the imposed stress because of the buoyant cap weight. The zero concentration gradient is also valid for the interface of the sediment and the cap, because the gradient of excess pore pressure is zero in the cap as a result of the relatively higher hydraulic conductivity of the cap material compared to that of the sediment. The boundary conditions at the sediment surface are

$$
p^{e}\left(L_{d}, t\right)=0, G \frac{2(1-v)}{1-2 v} \frac{\partial u\left(L_{d}, t\right)}{\partial z}=-\gamma_{b} d, \frac{\partial c_{f}\left(L_{d}, t\right)}{\partial z}=0 .
$$

The initial condition $(t=0)$ of the variable $p^{e}$ within the sediment region $\left(0<z<L_{d}\right)$ is considered to be represented by the applied stress because of the buoyant weight of the overburden capping materials, while the initial soil displacement in the sediment layer is zero. The initial solute concentration for the contaminated layer $\left(L_{d}-b<z<L_{d}\right)$ is equal to the reference solute mass concentration $\left(c_{0}\right)$, and the initial condition of the uncontaminated region $\left(0<z<L_{d}-b\right)$ is $c=0$ :

$$
\begin{gathered}
p^{e}(z, 0)=\gamma_{b} d, \\
u(z, 0)=0, \\
c_{f}\left(0<z<L_{d}-b, 0\right)=0, \\
c_{f}\left(L_{d}-b<z<L_{d}, 0\right)=c_{0} .
\end{gathered}
$$

\section{Cap Model}

The cap layer is assumed not to be subject to consolidation $\left(u_{c}=0\right)$. Because the influence of self-weigh is negligible, this assumption is acceptable and makes the computation simpler. Also, to compare our results with previous work generally, the cap material is composed of sandy to silty soils with relatively higher hydraulic conductivity compared to the underlying sediment layer (Alshawabkeh, Rahbar, and Sheahan, 2005). The contaminant flux induced by the advection process because of consolidating sediments can continuously travel through the cap layer and reach the cap surface $\left(z=L_{d}+d\right)$.

Darcy advective velocity $\left(v_{d}\right)$ was calculated by the average true pore-water velocity $\left(v_{f}\right)$ and the volume fraction $(\theta)$, i.e. $v_{d}=$ $\theta v_{f}$. Because of the relatively permeable capping material, the Darcy advective velocity throughout the capping depth $\left(v_{d}^{c}\right)$ is consequently assumed to be uniform, which depends on the consolidate-induced advective flow from the underlying sediments. In addition, no absorption occurs during contaminant transport within the cap materials $\left(c_{s}^{c}=0\right)$. Therefore, there is only one simple solute transport equation to dominate the nonreactive contaminant migration throughout the capping layer $\left(L_{d}<z<L_{d}+d\right)$ :

$$
S_{r}^{c} n_{0}^{c} \frac{\partial c_{f}^{c}}{\partial t}=S_{r}^{c} n_{0}^{c} D^{c} \frac{\partial^{2} c_{f}^{c}}{\partial z^{2}}-v_{d}^{c} \frac{\partial c_{f}^{c}}{\partial z}
$$

where $c_{f}^{c}$ is the solute concentration in the fluid phase of cap materials $\left(\mathrm{ML}^{-3}\right) ; S_{r}^{c}$ and $n_{0}^{c}$ are the degree of saturation and initial porosity of the cap layer, respectively; $D^{c}$ is the 


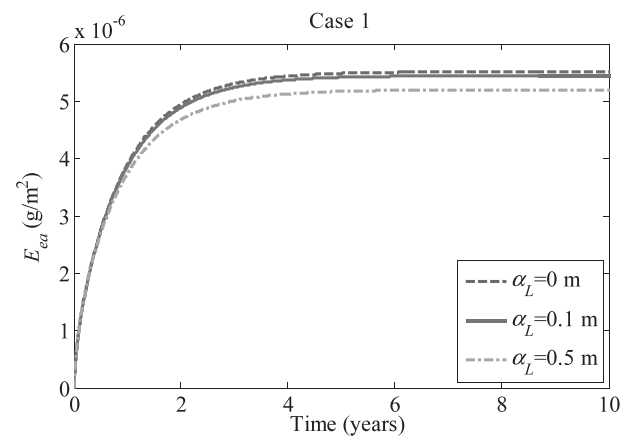

(a)

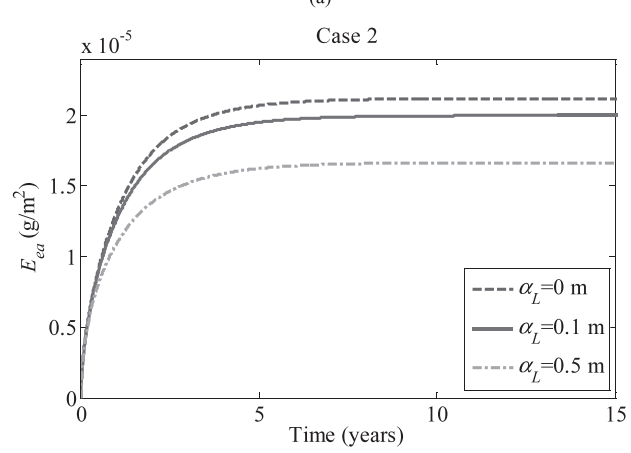

(b)

Figure 2. Influence of longitudinal dispersivity on sediment emission $\left(E_{e a}\right)$. (a) and (b) are for the illustrative cases 1 and 2, respectively. The release of contaminants from sediment to cap is higher in case 2 , where the difference made by considering longitudinal dispersivity is more pronounced.

hydrodynamic dispersion coefficient of the cap materials $\left(\mathrm{L}^{2} \mathrm{~T}^{-1}\right)$; and $v_{d}^{c}$ is the time-dependent Darcy advective velocity throughout the cap $\left(\mathrm{LT}^{-1}\right)$, which is equivalent to the Darcy advective velocity at the sediment's upper boundary and can be calculated from the sediment consolidation equations at $z=L_{d}^{-}$:

$$
v_{d}^{c}=-\frac{K}{\rho_{w} g} \frac{\partial p^{e}}{\partial z}+\left.S_{r} n_{0} \frac{\partial u}{\partial t}\right|_{z=L_{d}^{-}} .
$$

Unlike in Alshawabkeh, Rahbar, and Sheahan (2005), the saturation of the cap layer $\left(S_{r}^{c}\right)$ is taken into account in the present transport equation for the overlying cap in Equation (8). Furthermore, as mentioned previously, the main difference between the Darcy advective velocity determined from Equation (9) and that defined by Alshawabkeh, Rahbar, and Sheahan (2005) is the consideration of the velocity of solid particles $\left(v_{s}\right)$ because of sediment deformation. The resultant influence is discussed in the sensitivity analysis. Herein, the hydrodynamic dispersion coefficient of the cap materials $\left(D^{c}\right)$ is approximately equal to the effective diffusion coefficient of the $\operatorname{cap}\left(D_{e}^{c}\right)$.

The solute mass flux vector in the fluid phase $\left(f_{f}\right)$ was defined in Bear and Cheng (2010) by combining the advective flux and the dispersive flux that is controlled by Fick's law:

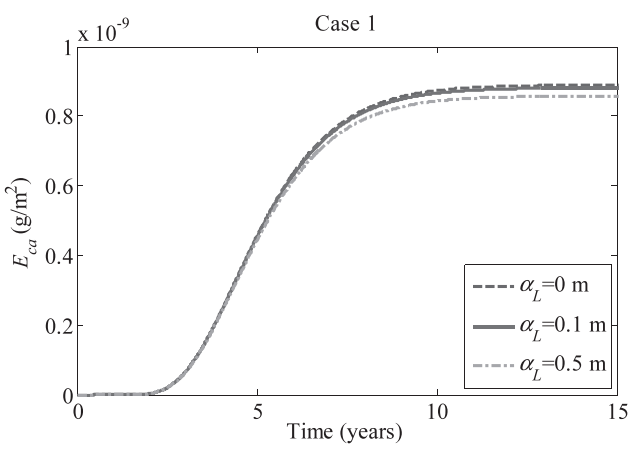

(a)

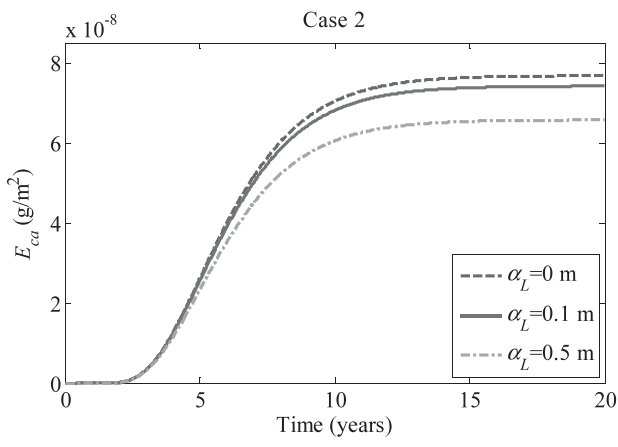

(b)

Figure 3. Influence of longitudinal dispersivity on cap emission $\left(E_{c a}\right)$. (a) and (b) are for the illustrative cases 1 and 2, respectively. The release of contaminants from cap to water body is higher in case 2 , where the difference made by considering longitudinal dispersivity is more pronounced.

$$
f_{f}=\theta v_{f} c_{f}-\theta D \frac{\partial c_{f}}{\partial z}=v_{d} c_{f}-\theta D \frac{\partial c_{f}}{\partial z},
$$

where $f f$ is the solute mass flux in the fluid phase $\left(\mathrm{MT}^{-1} \mathrm{~L}^{-2}\right)$ and the first and second terms on the right-hand side represent the advective flux $\left(f_{f a}\right)$ and the dispersive flux $\left(f_{f d}\right)$, respectively.

According to the description of the boundary condition at the sediment-cap interface provided by Alshawabkeh, Rahbar, and Sheahan (2005), the advective contaminant flux from the upper boundary of sediments (i.e. the sediment surface, $z=L_{d}^{-}$) induced by the Darcy advective velocity should be directly and wholly traveled through the lower boundary of caps (i.e. the cap bottom, $z=L_{d}^{+}$). Therefore, the contaminant flux traveling from the sediment to the cap $\left(f_{e c}\right)$ is expressed as

$$
f_{e c}=-S_{r}^{c} n_{0}^{c} D_{e}^{c} \frac{\partial c_{f}^{c}}{\partial z}+\left.v_{d}^{c} c_{f}^{c}\right|_{z=L_{d}^{+}}=\left.v_{d}^{c} c_{f}^{s}\right|_{z=L_{d}^{-}},
$$

where $c_{f}^{s}$ is the solute concentration in the fluid phase at the sediment's upper boundary $\left(\mathrm{ML}^{-3}\right)$.

The Danckwerts boundary condition is also adopted at the top of the overlying cap:

$$
\frac{\partial c_{f}^{c}\left(L_{d}+d, t\right)}{\partial z}=0
$$

The initial concentration of the cap layer is assumed to be zero: 


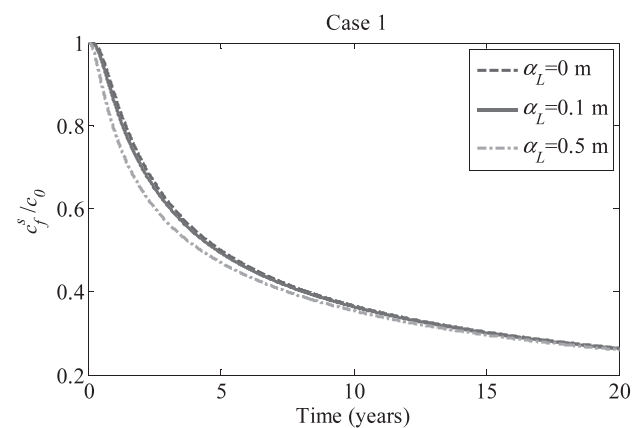

(a)

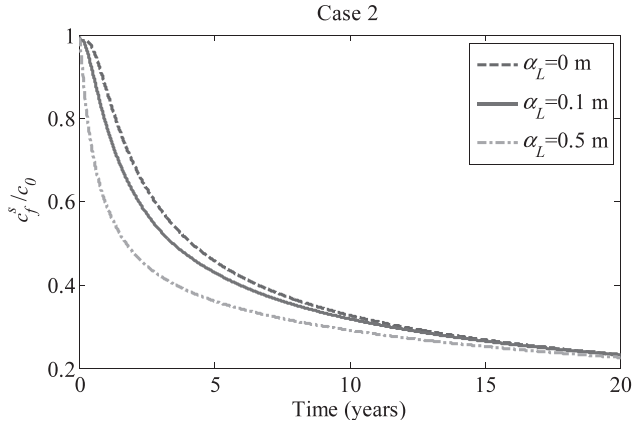

(b)

Figure 4. Influence of longitudinal dispersivity on normalized concentration at the top of the sediment $\left(c_{f}^{s} / c_{0}\right)$. (a) and (b) are for the illustrative cases 1 and 2 , respectively. The pollution level decreases faster when the longitudinal dispersivity is included.

$$
c_{f}^{c}\left(L_{d}<z<L_{d}+d, 0\right)=0 .
$$

\section{Numerical Model}

Based on the finite element method, the present onedimensional numerical model (i.e. the sediment-cap model) is established with the aid of the partial differential equation module in the COMSOL Multiphysics software (COMSOL Staff, 2008). The quadratic (second order) Lagrange element (i.e. the Lagrange finite element of order two with a dependent variable) is employed to discretize the system, which ensures a second order of accuracy in the simulation. The global element size assigned in each submodel is $10^{-2} \mathrm{~m}$, and the maximum locally refined mesh at the end and interior boundaries (where rapid changes may occur during the consolidation and transport processes) is $10^{-3} \mathrm{~m}$, with a growth rate of 1.2 . The subtimestep is set as $10^{-2}$ year.

\section{RESULTS}

In this section, a sensitivity analysis is carried out with two illustrative sediment examples to indicate the significance of new terms (i.e. longitudinal dispersivity, self-weight of sediments, spatial variation of porosity, SV, and CPW). First, these are considered for the case of a cap system, and then a simplified model is proposed.

Palermo et al. (1998) claimed that one of the most important design specifications for a successful capping project is to reduce or suppress the dissolved contaminant flux into the

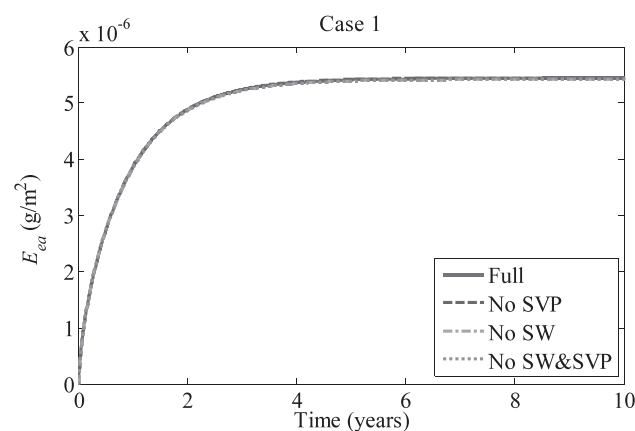

(a)

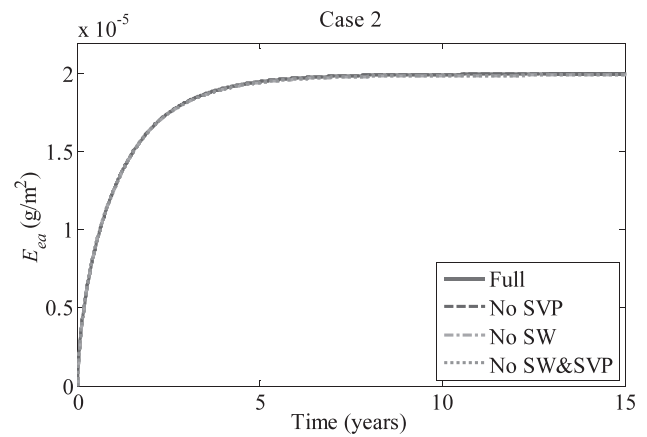

(b)

Figure 5. Influence of self-weight (SW) and spatial variation of porosity (SVP) on sediment emission $\left(E_{e a}\right)$. In both cases, the effects of SW and SVP on the pollutant emissions from sediment to cap are negligible.

water column. A commonly used metric mentioned by many investigators is the "breakthrough time," which is determined as the time required to reach the peak breakthrough concentration or the predetermined concentration (Zhang et $a l .$, 2012). Herein, the peak concentration is adopted to characterize the breakthrough time of the concentration at the top of the cap.

To emphasize the difference in the advective flux $\left(f_{f a}\right)$ made by the new terms, the advective solute emission $\left(E_{a}\right.$, the cumulative contaminant mass outflow per unit area because of the advective flow) introduced by Zhang et al. (2012) is employed in this study:

$$
E_{a}=\int_{0}^{t} f_{f a} d t
$$

Two sediments are used as illustrative examples (Table 1) that can sufficiently indicate the potential influence of each examined term on consolidation-induced contaminant transport. A simplified model is proposed for the cap system based on the conclusion drawn from the sensitivity analysis.

\section{Sensitivity Analysis}

As illustrated in Figures 2 to 4, the influence of longitudinal dispersivity becomes more significant in the relatively softer and more permeable sediment (with a higher Peclet number). Moreover, the final advective solute emission from the sediment and cap surfaces ( $E_{e a}$ and $E_{c a}$, respectively) can be decreased proportionally with the increasing longitudinal dispersivity. 


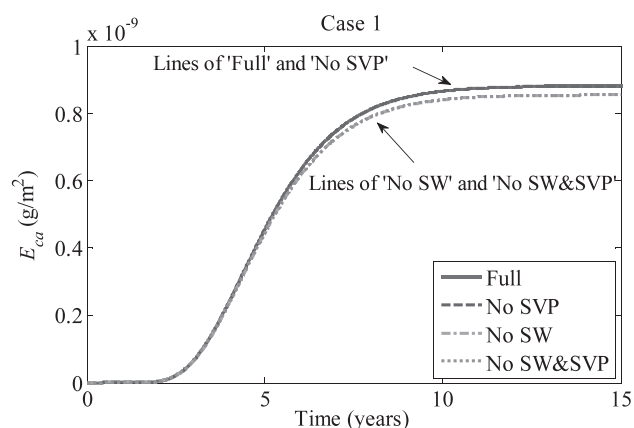

(a)

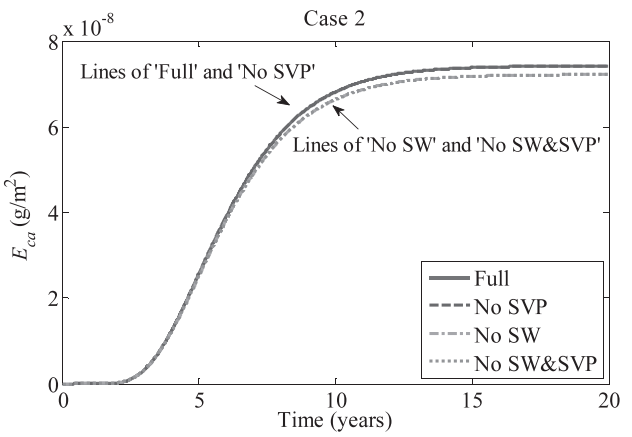

(b)

Figure 6. Influence of self-weight (SW) and spatial variation of porosity (SVP) on cap emission $\left(E_{c a}\right)$. In both cases, the effects of SW and SVP on the pollutant emissions from the cap to the overlying water body are negligible.

Figures 5 and 6 demonstrate that the influenced Darcy advective velocity caused by self-weight in the consolidation equation in Equation (2) has a more visible effect on the cap emission $\left(E_{c a}\right)$. However, it is reasonable to ignore the spatial variation of porosity and SV term in the transport equation in Equation (4) for both cases.

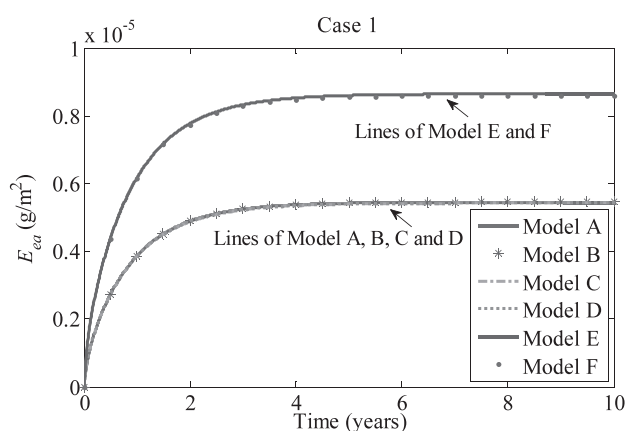

(a)

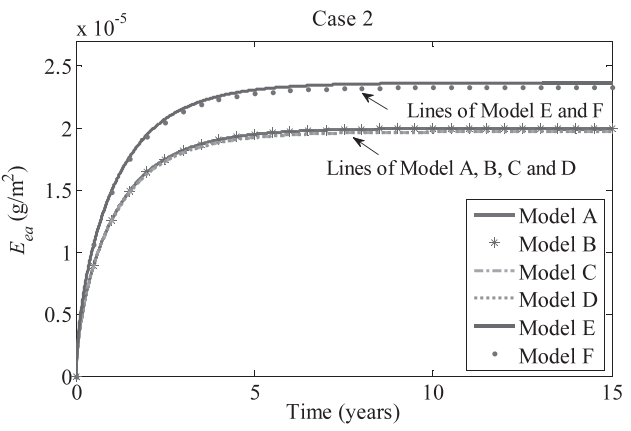

(b)

Figure 7. Influence of $\mathrm{SV}$ on sediment emission $\left(E_{e a}\right)$. Compared with reference model $\mathrm{A}$, models $\mathrm{E}$ and $\mathrm{F}$ with the Darcy advective velocity excluding SV overestimate the pollutant emission from sediment to cap.

To examine the influence of SV on solute transport through the consolidating sediment and overlying cap, six models are established for the two soil examples; the model details are listed in Table 2 (see also Figures 7-9). For models A to D, the Darcy advective velocity $\left(v_{d}^{c}\right)$ arises from the average true porewater velocity at the upper boundary of sediments $\left(v_{f}^{c}\right)$,

Table 2. Details of the models in the sensitivity analysis for the influence of longitudinal dispersivity.

\begin{tabular}{|c|c|c|}
\hline Model & Description & Details \\
\hline A & $\begin{array}{l}\text { Darcy advective velocity }\left(v_{d}^{c}\right) \\
\text { computed by Equation }(9) \text {, with } \\
\text { the complete transport equation } \\
\text { in Equation (4) }\end{array}$ & $v_{d}^{c}=-\frac{K}{\rho_{w} g} \frac{\partial p^{e}}{\partial z}+\left.n_{0} S_{r} \frac{\partial u}{\partial t}\right|_{z=L_{d}^{-}}$ \\
\hline B & $\begin{array}{l}v_{d}^{c} \text { computed by Equation (9); the } \\
\text { "sources/sinks" } v_{s} \text { term is ignored } \\
\text { in the transport equation in } \\
\text { Equation (4) }\end{array}$ & $v_{d}^{c}=-\frac{K}{\rho_{w} g} \frac{\partial p^{e}}{\partial z}+\left.n_{0} S_{r} \frac{\partial u}{\partial t}\right|_{z=L_{d}^{-}} ; S_{r} n_{0} \beta \frac{\partial u}{\partial t} \frac{\partial p^{e}}{\partial z} c_{f}$ in Equation (4) is omitted \\
\hline $\mathrm{C}$ & $\begin{array}{l}v_{d}^{c} \text { computed by Equation (9); the } \\
\text { advective } v_{s} \text { term is ignored in the } \\
\text { transport equation in Equation } \\
\text { (4) }\end{array}$ & $v_{d}^{c}=-\frac{K}{\rho_{w} g} \frac{\partial p^{e}}{\partial z}+\left.n_{0} S_{r} \frac{\partial u}{\partial t}\right|_{z=L_{d}^{-}} ;\left[S_{r} n_{0}+\left(1-n_{0}\right) \rho_{s} K_{d}\right] \frac{\partial u}{\partial t} \frac{\partial c_{f}}{\partial z}$ in Equation (4) is omitted \\
\hline $\mathrm{D}$ & $\begin{array}{l}v_{d}^{c} \text { computed by Equation (9), with } \\
\text { no } v_{s} \text { term in the transport } \\
\text { equation in Equation }(4)\end{array}$ & $v_{d}^{c}=-\frac{K}{\rho_{w} g} \frac{\partial p^{e}}{\partial z}+\left.n_{0} S_{r} \frac{\partial u}{\partial t}\right|_{z=L_{d}^{-}} ;\left[S_{r} n_{0}+\left(1-n_{0}\right) \rho_{s} K_{d}\right] \frac{\partial u}{\partial t} \frac{\partial c_{f}}{\partial z}$ and $S_{r} n_{0} \beta \frac{\partial u}{\partial t} \frac{\partial p^{e}}{\partial z} c_{f}$ in Equation (4) are omitted \\
\hline $\mathrm{E}$ & $\begin{array}{l}v_{d}^{c} \text { computed by Equation (16), with } \\
\text { the complete transport equation } \\
\text { in Equation (4) }\end{array}$ & $v_{d}^{c}=-\left.\frac{K}{\rho_{w} g} \frac{\partial p^{e}}{\partial z}\right|_{z=L_{d}^{-}}$ \\
\hline $\mathrm{F}$ & $\begin{array}{l}v_{d}^{c} \text { computed by Equation (16), with } \\
\text { the transport equation in } \\
\text { Equation (4) without the } v_{s} \text { term }\end{array}$ & $v_{d}^{c}=-\left.\frac{K}{\rho_{w} g} \frac{\partial p^{e}}{\partial z}\right|_{z=\dot{I}_{d}}\left[S_{r} n_{0}+\left(1-n_{0}\right) \rho_{s} K_{d}\right] \frac{\partial u}{\partial t} \frac{\partial c_{f}}{\partial z}$ and $S_{r} n_{0} \beta \frac{\partial u}{\partial t} \frac{\partial p^{e}}{\partial z} c_{f}$ in Equation (4) are omitted \\
\hline
\end{tabular}




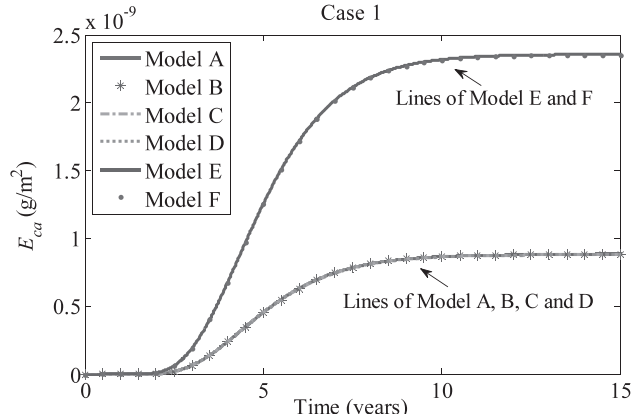

(a)

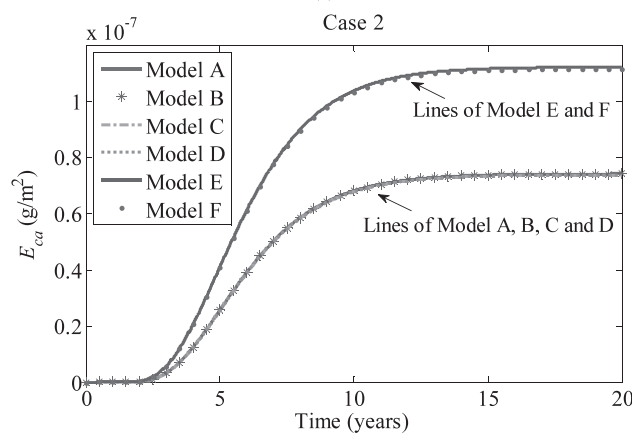

(b)

Figure 8. Influence of SV on cap emission $\left(E_{c a}\right)$. Compared with reference model A, models $\mathrm{E}$ and $\mathrm{F}$ with the Darcy advective velocity excluding SV overestimate the pollutant emission from the cap to the overlying water body.

whereas for models $\mathrm{E}$ and $\mathrm{F}$, the Darcy advective velocity is directly characterized by the specific discharge relative to solid $\left(q_{r}^{c}\right)$ by ignoring the $\mathrm{SV}\left(v_{s}=0\right)$, which is analogous to the definition in Alshawabkeh, Rahbar, and Sheahan (2005). Simultaneously, to recognize the relative importance of each $\mathrm{SV}$ term in the transport equation, the SV terms $\left(S_{r} n_{0} \beta \frac{\partial u}{\partial t} \frac{\partial p^{e}}{\partial z} c_{f}\right.$ and $\left.\frac{\partial c_{f}}{\partial z}\left[S_{r} n_{0}+\left(1-n_{0}\right) \rho_{s} K_{d}\right] \frac{\partial u}{\partial t}\right)$ in Equation (4) are ignored in models $\mathrm{B}$ and $\mathrm{C}$, respectively. Models $\mathrm{D}$ and $\mathrm{F}$ are governed by the transport equation without the SV terms.

Based on the preceding results, some preliminary conclusions can be drawn. The potential influence of the difference in the Darcy advective velocity (caused by self-weight and different definitions of $v_{d}^{c}$ ) on the cap emission $\left(E_{c a}\right)$ is more significant compared to that on the sediment emission $\left(E_{e a}\right)$. However, the affected contaminant concentration at the upper boundary of sediments (caused by the dispersivity, spatial variation of porosity, and SV terms in the transport equation) has an effect on the sediment emission in a similar way but a weak effect on the cap emission.

To evaluate the influence of the CPW on the advective solute emission, four models are constructed in this section; the details are tabulated in Table 3. Figures 10 to 12 illustrate that it is necessary to account for CPW in the sediment consolidation model when simulating the contaminant migration through the cap system but that the CPW terms in the transport equation matter little and can be omitted in both cases.

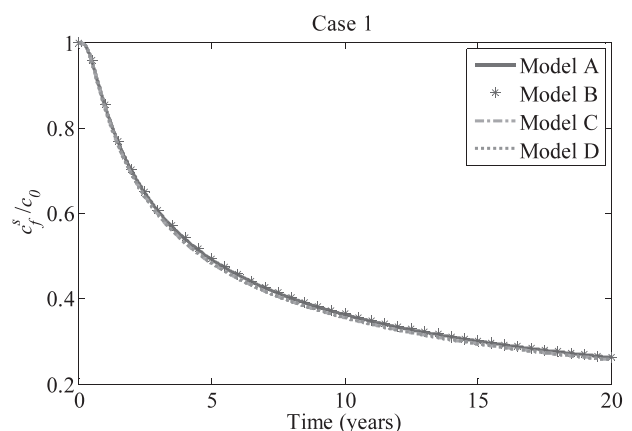

(a)

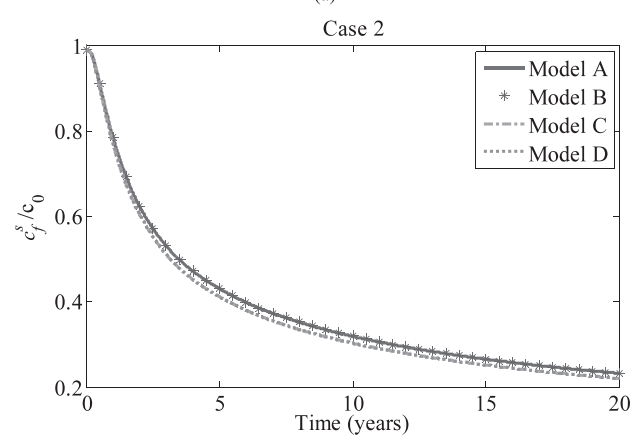

(b)

Figure 9. Influence of SV on normalized concentration at the top of the sediment $\left(c_{f}^{s} / c_{0}\right)$. This is to identify the relative importance of terms corresponding to SV in the transport equation. It indicates that SV does not notably affect the predicted concentration at the top of the sediment.

Based on the aforementioned results, the advection-dispersion equation for sediment can be simplified as

$$
\begin{aligned}
{\left[S_{r} n_{0}\right.} & \left.+\left(1-n_{0}\right) \rho_{s} K_{d}\right] \frac{\partial c_{f}}{\partial t}=S_{r} n_{0} D_{e} \frac{\partial^{2} c_{f}}{\partial z^{2}}-\alpha_{L} \frac{K}{\rho_{w} g} \frac{\partial p^{e}}{\partial z} \frac{\partial^{2} c_{f}}{\partial z^{2}} \\
& +\frac{\partial c_{f}}{\partial z}\left\{\frac{K}{\rho_{w} g} \frac{\partial p^{e}}{\partial z}-\alpha_{L} S_{r} \frac{\partial^{2} u}{\partial z \partial t}-\left[S_{r} n_{0}+\left(1-n_{0}\right) \rho_{s} K_{d}\right] \frac{\partial u}{\partial t}\right\} .
\end{aligned}
$$

\section{DISCUSSION}

In this section, the effects of sediment and geometric properties (i.e. absorption, degree of sediment saturation, cap

Table 3. Details of the models in the sensitivity analysis for the influence of

\begin{tabular}{|c|c|c|}
\hline Model & Description & Details \\
\hline A & $\begin{array}{l}\text { The complete governing } \\
\text { equations }\end{array}$ & \\
\hline B & $\begin{array}{l}\text { The CPW is ignored in the } \\
\text { transport equation with the } \\
\text { complete consolidation } \\
\text { equations }\end{array}$ & $\beta=0$ in Equation $(4)$ \\
\hline $\mathrm{C}$ & $\begin{array}{l}\text { The CPW is ignored in the fluid } \\
\text { storage equation with the } \\
\text { complete transport equation }\end{array}$ & $\beta=0$ in Equation (1) \\
\hline D & $\begin{array}{l}\text { The CPW is ignored in the } \\
\text { sediment model }\end{array}$ & $\beta=0$ in Equations (1) and (4) \\
\hline
\end{tabular}
$C P W$. 


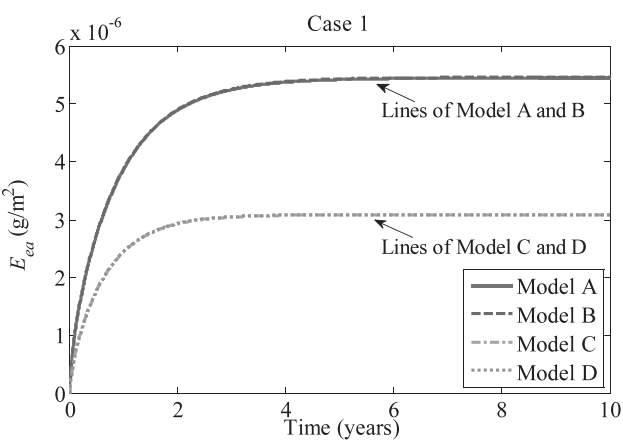

(a)

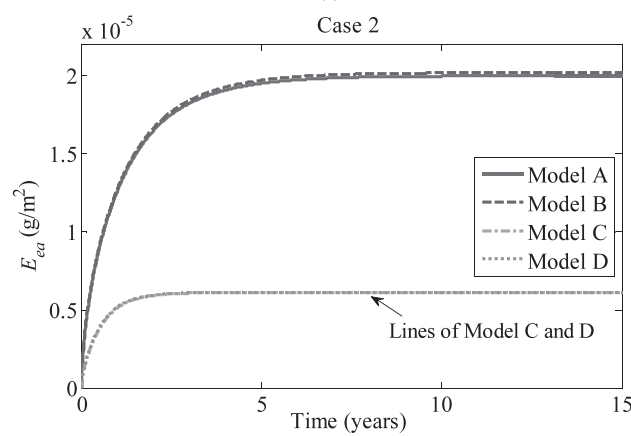

(b)

Figure 10. Influence of CPW on sediment emission $\left(E_{e a}\right)$. It indicates that ignoring the CPW term in the transport equation only slightly overestimates the pollutant emission from sediment to cap. However, CPW cannot be ignored in the consolidation equations; otherwise, $E_{e a}$ is significantly underestimated.

thickness, and sediment depth) on the contaminant migration through the deforming sediment-and-cap layer are examined by a parametric study using the simplified model. The parameters of case 1 , tabulated in Table 1, are adopted for the benchmark example in this parametric study.

\section{Effect of Adsorption}

Figure 13a indicates that at the sediment surface, the concentration for a contaminant that has less affinity (a lower $K_{d}$ value) experiences a sharper decrease induced by the advection and dispersion processes. The normalized concentration $\left(c_{f}^{s} / c_{0}\right)$ at the end of 20 years for $K_{d}=10 \mathrm{~L} / \mathrm{kg}$ is about 0.93 , while the value for $K_{d}=0 \mathrm{~L} / \mathrm{kg}$ is only 0.27 . This is because the introduction of adsorption can strongly retard the rate of contaminant removal from the contaminated sediment layer, as most of the contaminant mass is adsorbed to sediments and serves as a long-term source. As shown in Figure 13b, there is a great gap in the final sediment emission $\left(E_{e a}\right)$ between the cases with and those without adsorption. However, the final emission is slightly increased when $K_{d}$ rises from 1 to $5 \mathrm{~L} / \mathrm{kg}$. Moreover, comparing the contaminant concentration curves of $K_{d}=5$ and $10 \mathrm{~L} / \mathrm{kg}$ (shown in Figure 13a), it is evident that because the difference in $c_{f}^{s} / c_{0}$ over the consolidation period (approximately during the first 5 years) is not obvious, the further increase of the partitioning coefficient from 5 to $10 \mathrm{~L} / \mathrm{kg}$ leads to little effect on the profile of $E_{e a}$ (Figure 13b). Therefore,

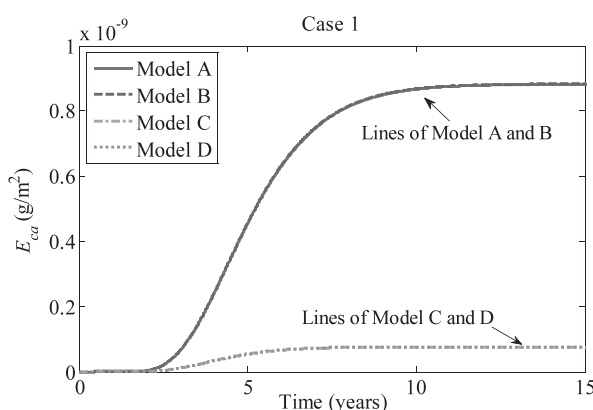

(a)

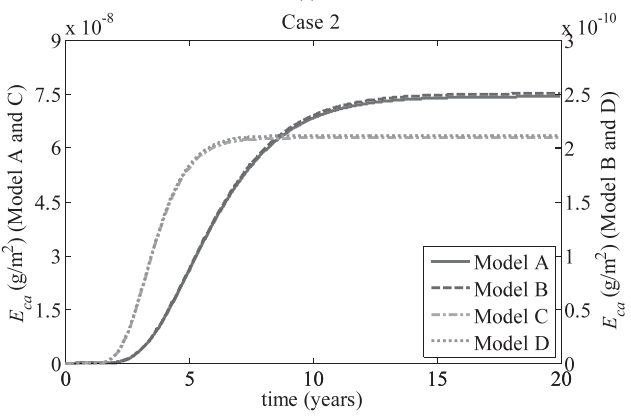

(b)

Figure 11. Influence of CPW on cap emission $\left(E_{c a}\right)$. It indicates that ignoring the CPW term in the transport equation only slightly overestimates the pollutant emission from sediment to cap.

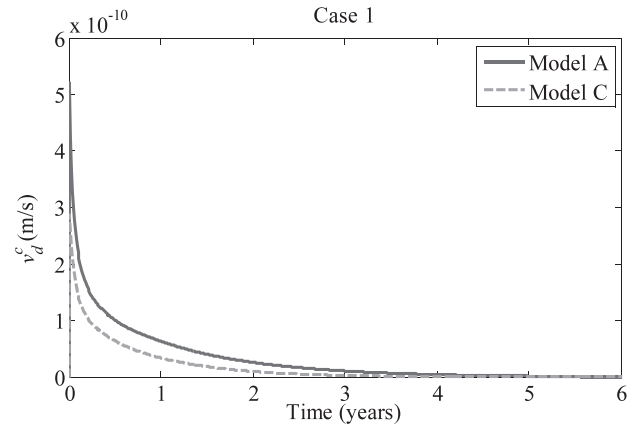

(a)

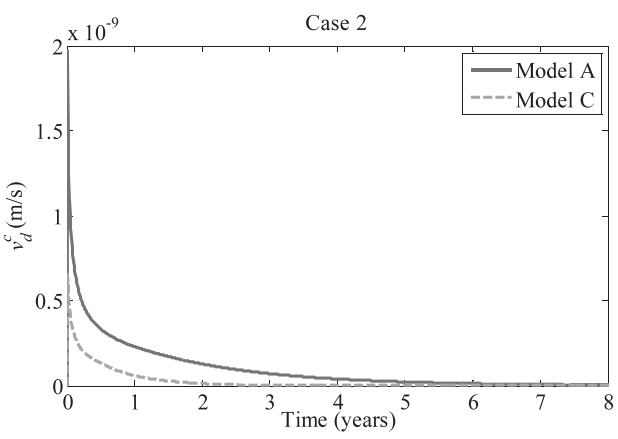

(b)

Figure 12. Influence of CPW on Darcy advective velocity $\left(v_{d}^{c}\right)$. Neglecting CPW in model $\mathrm{C}$ is found to result in lower $v_{d}^{c}$. 

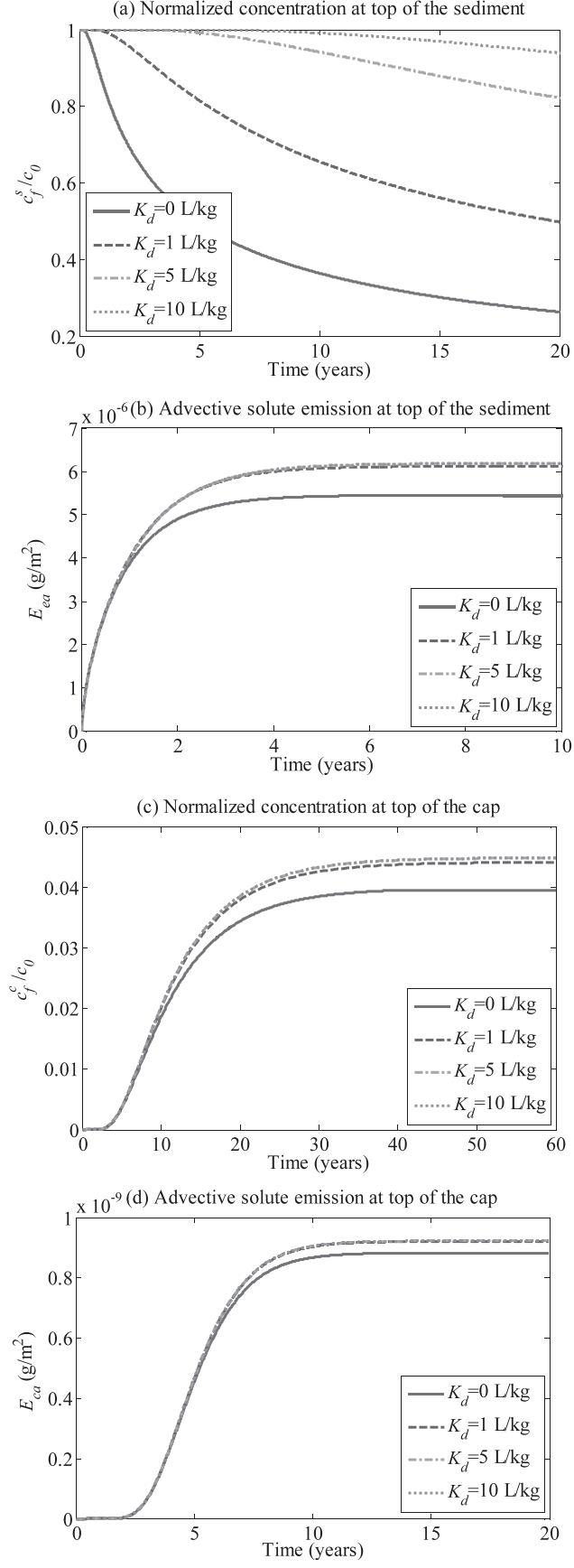

Figure 13. Influence of absorption $\left(K_{d}\right)$. The higher affinity of a pollutant corresponding to a larger $K_{d}$ can lead to a higher level of pollutant concentration at the sediment-cap interface. However, it may not retard the advective emission of the pollutant from the cap to the overlying water body.

a critical number of $K_{d}$ can be determined as the final $E_{e a}$ stops increasing. It can be speculated that a longer process of dissipation of excess pore pressure can contribute to a more significant effect of adsorption on $E_{e a}$ and a bigger critical $K_{d}$ number.
Figure 13c reveals that including the contaminant absorption increases the breakthrough concentration at the top of the cap $\left(c_{f}^{s} / c_{0}\right)$, but this effect vanishes as the $K_{d}$ value increases. It can be deduced that the breakthrough concentration directly depends on the advective solute emission from the sediment surface $\left(E_{e a}\right)$, which is treated as the contaminant source for the solute advection and diffusion within the cap layer. In other words, higher $E_{\text {ea }}$ can result in a higher breakthrough concentration. However, the adsorption process has no discernible impact on the breakthrough time (Figure 13c). Compared to the curves displayed in Figure 13b, the similar but weakened impact of adsorption on cap emission $\left(E_{c a}\right)$ is also found from Figure $13 \mathrm{~d}$, where the final $E_{c a}$ value is slightly enhanced by introducing the adsorption process but the increased $K_{d}$ from 1 to $10 \mathrm{~L} / \mathrm{kg}$ contributes little to $E_{c a}$.

Because a "long-term" contaminant source in the contaminated sediment layer is created by incorporating the contaminant absorption, more contaminants could be transferred into the cap layer and released into the overlying water column. With the increasing $K_{d}$ value, the final emission is further enhanced, but when $K_{d}$ exceeds a critical number, the finial emission reaches the maximum value and no longer increase. The critical $K_{d}$ number is likely to be related to the sediment consolidation process. Furthermore, the breakthrough concentration at the cap-water interface is directly proportional to the ultimate $E_{e a}$.

\section{Effects of Degree of Sediment Saturation}

The value of CPW ( $\beta$ ) can be drastically affected by a small change of air content in offshore sediments. Thus, it is beneficial to examine the influence of the saturation of underlying sediments on the consolidation-induced contaminant migration through sediments and caps. A range of degrees of saturation from 0.85 to 1.0 is selected, and the results are shown in Figure 14.

According to the contaminant concentration at the sediment surface $\left(c_{f}^{s} / c_{0}\right)$ indicated in Figure 14a, the initial significantly reduction (approximately in the first 3 years) is driven simultaneously by advection and dispersion (particularly hydrodynamic dispersion). Because of the enhanced Darcy advective velocity $\left(v_{d}^{c}\right)$ caused by the larger $\beta$ (shown in Figure $14 \mathrm{e}), c_{f}^{s} / c_{0}$ in the less saturated soil is further decreased and the resulting difference remains unchanged during the postconsolidation period, when contaminant transport is solely dominated by the diffusion process. Figure 14b indicates that the final advective solute emission from the sediment-cap interface $\left(E_{e a}\right)$ is enhanced considerably as the sediment contains more discrete bubbles. This can be mainly attributed to the more significant consolidation process (shown in Figure 14e) in sediments with a lower degree of saturation, even though a slightly lower concentration is obtained at the sediment surface (Figure 14a).

As illustrated in Figure 14c, the variation of saturation of sediments $\left(S_{r}\right)$ has little effect on the transit time for contaminants to break through the cap layer; that is, the time required by each case to get the peak breakthrough concentration is identical. In contrast, because of the enhanced contaminant flux through the surface of partially saturated 

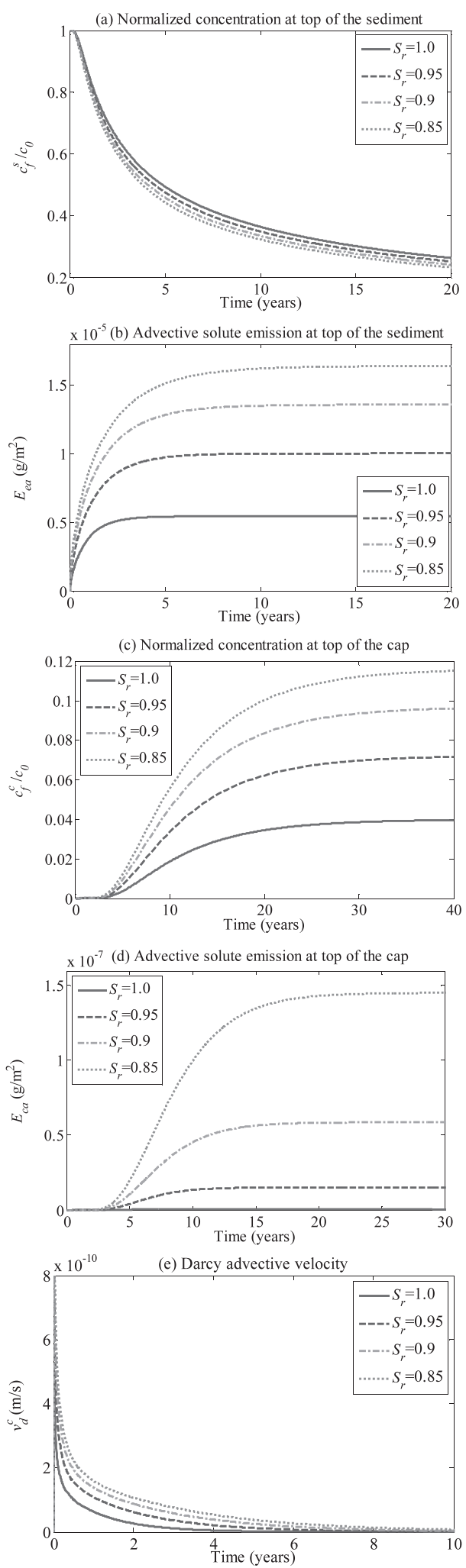

Figure 14. Influence of the degree of sediment saturation $\left(S_{r}\right)$. In the presence of occluded air bubbles, the consolidation process is enhanced greatly in the partially saturated sediment; thus, the resulting advective sediments (Figure 14b), the breakthrough concentration at the cap surface (after the advection and diffusion processes) becomes higher with the lower degree of saturation. As shown in Figure 14c, the final $E_{c a}$ value for the fully saturated soil $\left(S_{r}\right.$ $=1.0$ ) is roughly two orders of magnitude lower than that for $S_{r}$ $=0.85$. It is concluded that both the enhanced Darcy advective velocity and higher contaminant breakthrough result in a substantial rise in the ultimate $E_{c a}$.

Compared to the numerical results obtained from the case of $S_{r}=1.0$, the consolidation process is enhanced greatly in the partially saturated sediment and thus the resulting $E_{c a}$ is increased by several orders of magnitude. It can be deduced that the effectiveness of a cap system could be overestimated by the previous work of Alshawabkeh, Rahbar, and Sheahan (2005) where the Terzaghi consolidation theory is only valid for the consolidation problem under fully saturated conditions. Therefore, it is necessary to consider the effect of partially saturated sediments when evaluating contaminant transport within the capped consolidating sediment.

\section{Effects of Cap Thickness}

The influence of cap thickness on consolidation-induced contaminant transport through the capped sediments is investigated in this section. Four cap layers constructed using similar cap material but with different dimensions ranging from 30 to $75 \mathrm{~cm}$ are tested, and the results are presented in Figure 15

Figure 15a indicates that the variation of cap thickness has no discernible effect on the contaminant concentration at the sediment surface $\left(c_{f}^{s} / c_{0}\right)$. As shown in Figure 15e, the enhanced sediment consolidation caused by the bigger surcharge leads to greater Darcy advective velocity, which accelerates the advective contaminant flux and results in a higher final advective solute emission from sediment-cap interface (shown in Figure 15b). However, because of the same sediment parameters (including the shear modulus, hydraulic conductivity, and corresponding coefficient of consolidation) applied in each case, the amount of time spent by each case on the dissipation of excess pore pressure is the same (around 6 years). Therefore, the profile of the sediment emission $\left(E_{e a}\right)$ for each case has the similar shape and timescale.

As shown in Figure 15c, the cap thickness can significantly affect the contaminant breakthrough at the cap surface $\left(c_{f}^{s} / c_{0}\right)$. Although the relatively higher Darcy advective velocity is generated by a larger capping surcharge, contaminants still spend far more time reaching the top of the cap. Because of a longer transport distance, it takes around 4 years for contaminants to get the cap surface in the case of 75 $\mathrm{cm}$, but only a few months are required for the case of $30 \mathrm{~cm}$. Subsequently, the contaminants transported by the advective flux accumulate more rapidly at the cap surface for a thinner cap layer over the consolidation period (approximately in the first 6 years), which leads to a huge gap in the contaminant

solute emission at the cap surface $\left(E_{c a}\right)$ is increased by several orders of magnitude. 

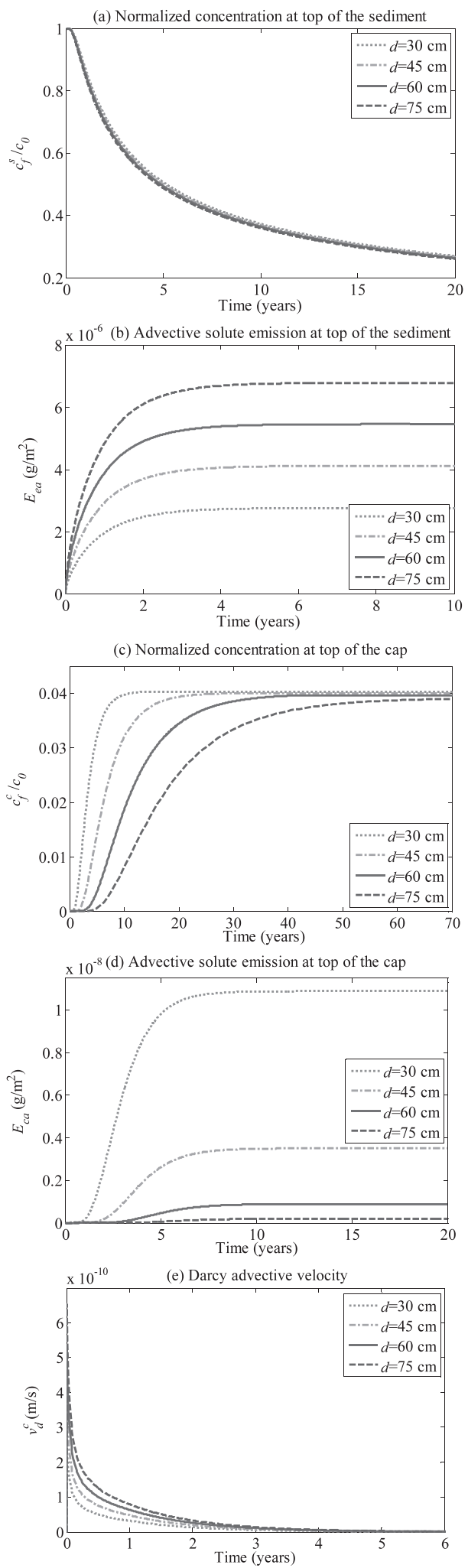

Figure 15. Influence of cap thickness $(d)$. Increasing the thickness of the cap is found to impede the pollutant discharge. A thicker cap layer can weaken the influence of advective contaminant transport because of consolidation on the cap emission by storing contaminants in its own body. breakthrough curves $\left(c_{f}^{s} / c_{0}\right)$ at the end of this period. In the postconsolidation period, the diffusion process contributes to the further increase of $c_{f}^{s} / c_{0}$ in a thicker cap layer. Figure $15 \mathrm{c}$ indicates that compared to other cases, the concentration of case $75 \mathrm{~cm}$ experiences a gentler and longer increase to get to the breakthrough concentration and thus a longer breakthrough time. This can be attributed to the higher advective solute emission from the sediment surface $\left(E_{e a}\right)$ induced by the bigger cap loading (Figure 15b). However, the breakthrough concentration of each case is located at the same level (shown in Figure 15c); that is, the variation of cap thickness has no effect on the breakthrough concentration. Figure $15 \mathrm{~d}$ illustrates that the cap emission $\left(E_{c a}\right)$ from a thin cap $(35 \mathrm{~cm})$ is substantially increased by several orders of magnitude when comparing with that from a thick cap $(70 \mathrm{~cm})$. Moreover, according to $E_{e a}$ indicated in Figure $15 \mathrm{~b}$, it can be deduced that a thicker cap layer can weaken the influence of sediment consolidation on $E_{c a}$ by storing contaminants in its own body.

Consequently, the increasing cap thickness can improve the performance of the cap system by retarding and limiting the contaminant discharge into the overlying water column. However, the cap thickness is found to have no effect on the breakthrough concentration at the cap surface.

\section{Effects of Sediment Depth}

As an engineered project, the successful in situ capping system should be conducted with a careful and systematic site investigation for the seabed sediment characterization. One of the most essential factors that could directly control the consolidation process is the dimension of the sediment layer. In this section, the sediment depth $\left(L_{d}\right)$ is considered to vary between 10.0 and $2.5 \mathrm{~m}$, and the resultant influence on the consolidation and solute transport processes is shown in Figure 16.

As shown in Figure 16a, there is little effect caused by the decreasing sediment depth on the profiles of contaminant concentration at the sediment surface $\left(c_{f}^{s} / c_{0}\right)$, except for $L_{d}=$ $2.5 \mathrm{~m}$, where the simulation result is more likely to be affected by the fixed impermeable bottom $(z=0)$ because of a small seabed depth. Figure 16e indicates that the variation of sediment depth has no impact on the rate of consolidation initially, but the consolidation process lasts longer as the sediment depth increases, which leads to a gentler attenuation of the Darcy advective velocity. Therefore, the final gap in the contaminant emission from the sediment-cap interface (illustrated in Figure 16b) can be simply ascribed to the difference in Darcy advective velocity that acts as the carrier of contaminants.

Based on the contaminant breakthrough curve $\left(c_{f}^{s} / c_{0}\right)$ indicated in Figure 16c, increasing the sediment depth from 2.5 to $10 \mathrm{~m}$ results in a higher breakthrough concentration, because more water emission provides more contaminant fluxes traveling from the sediment surface into the cap layer. However, the effect of $L_{d}$ on the breakthrough time is not noticeable. As shown in Figure 16d, compared to the case of $L_{d}$ $=5.0 \mathrm{~m}$, the cap emission $\left(E_{c a}\right)$ with $L_{d}=10.0 \mathrm{~m}$ spends more time (roughly 40 years) getting the maximum value, which is approximately two orders of magnitude higher than that from 

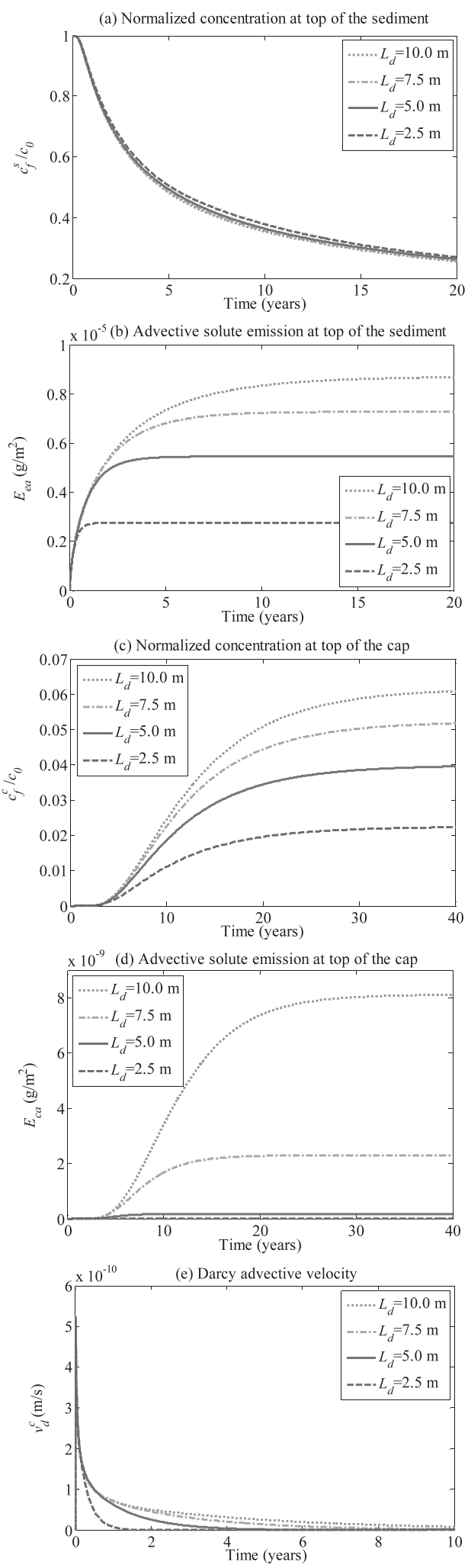

Figure 16. Influence of sediment depth $\left(L_{d}\right)$. In the presence of consolidation-induced transport of the contaminant, the ultimate cap emission can be significantly increased when the sediment depth increases.
$L_{d}=5.0 \mathrm{~m}$. It can be inferred that with the increasing sediment depth, both the extended consolidation process (Figure 16e) and the resultant significantly increased contaminant breakthrough (Figure 16c) contribute to a sharper increase in the cap emission $\left(E_{c a}\right)$ over a longer period, resulting in huge gaps in the final cap emission.

It is thus concluded that the thicker sediment produces a longer period of consolidation, which enhances the final advective solute emission from the sediment-cap interface followed by a higher breakthrough concentration at the cap surface. Moreover, the ultimate cap emission is significantly increased by several orders of magnitude as the sediment depth increases. Consequently, it is important to account for the sediment depth during the cap design process.

\section{CONCLUSION}

This paper presents a one-dimensional sediment-cap model to simulate contaminant transport within capped deforming sediments that is subject to surcharge loading imposed by an overlying cap layer. According to the sensitivity analysis, a simplified model is proposed, and then a parametrical study is performed using the simplified model.

When calculating the Darcy advective velocity, ignoring the SV component (as done by previous works) could have the potential to seriously underestimate the effectiveness of a cap system, especially in the stiffer and less permeable sediment. The mechanical dispersion (longitudinal dispersivity) of sediment becomes more important as the Peclet number increases, and the effect of the advective SV term in the transport equation depends on the solute adsorption.

The contaminant absorption can form a long-term contaminant source and significantly enhance the total contaminant emission into the water column. But the promotion diminishes and finally disappears as the partitioning coefficient increases to reach the critical $K_{d}$ number, which is mainly determined based on the sediment consolidation performance.

Less saturated sediments (corresponding to a higher value of CPW) accelerate the contaminant flux through the cap layer, resulting in higher advective solute emission at the cap surface because of the more significant and longer-lasting consolidation process.

A thick cap layer can effectively prevent contaminants releasing from the top of the cap by delaying the breakthrough time, though the variation of the cap thickness has no effect on the final level of the breakthrough concentration. Moreover, a larger sediment depth provides more consolidation by prolonging the process of the pore-water expulsion. Thus, the solute advection induced by the sediment consolidation is significantly enhanced, and the total cap emission is significantly increased by several orders of magnitude.

\section{ACKNOWLEDGMENTS}

This research was funded by the National Natural Science Foundation of China (Grant No. 51308259), Natural Science Foundation of the Jiangsu Higher Education Institutions of China (Grant No. 13KJB610004), and the Foundation for the advanced talent of Jiangsu University, China (Grant No. 13JDG060). 


\section{LITERATURE CITED}

Allison, J.D. and Allison, T.L., 2005. Partition Coefficients for Metals in Surface Water, Soil, and Waste. Washington, DC: U.S. Environmental Protection Agency Publication, EPA 600-R-05074, 85p.

Aloupi, M. and Angelidis, M.O., 2001. Normalization to lithium for the assessment of metal contamination in coastal sediment cores from the Aegean Sea, Greece. Marine Environmental Research, 52(1), 1 12.

Alshawabkeh, A.N.; Rahbar, N., and Sheahan, T., 2005. A model for contaminant mass flux in capped sediment under consolidation. Journal of Contaminant Hydrology, 78(3), 147-165.

Arega, F. and Hayter, E., 2008. Coupled consolidation and contaminant transport model for simulating migration of contaminants through the sediment and a cap. Applied Mathematical Modelling, $32(11), 2413-2428$.

Bear, J. and Cheng, A.H.D., 2010. Modeling Groundwater Flow and Contaminant Transport. New York: Springer, 834p.

Bert, V.; Seuntjens, P.; Dejonghe, W.; Lacherez, S.; Thuy, H.T.T., and Vandecasteele, B., 2009. Phytoremediation as a management option for contaminated sediments in tidal marshes, flood control areas and dredged sediment landfill sites. Environmental Science and Pollution Research, 16(7), 745-764.

COMSOL Staff, 2008. COMSOL Multiphysics User's Guide. Hatfield, United Kingdom: COMSOL.

Danckwerts, P.V., 1953. Continuous flow systems: Distribution of residence times. Chemical Engineering Science, 2(1), 1-13.
Fredlund, D. and Rahardjo, H., 1993. Soil Mechanics for Unsaturated Soil. New York: Wiley Interscience.

Liu, C.; Jay, J.A., and Ford, T.E., 2001. Evaluation of environmental effects on metal transport from capped contaminated sediment under conditions of submarine groundwater discharge. Environmental Science \& Technology, 35(22), 4549-4555.

Massoudieh, A.; Bombardelli, F.A., and Ginn, T.R., 2010. A biogeochemical model of contaminant fate and transport in river waters and sediments. Journal of Contaminant Hydrology, 112(1-4), 103117.

Palermo, M.; Maynord, S.; Miller, J., and Reible, D., 1998. Guidance for In-Situ Subaqueous Capping of Contaminated Sediments. Appendix C: Case Studies on Geotechnical Aspects of In-Situ Sand Capping. Chicago: Great Lakes National Program Office, pp. C1-C20.

Peters, G.P. and Smith, D.W., 2002. Solute transport through a deforming porous medium. International Journal for Numerical and Analytical Methods in Geomechanics, 26(7), 683-717.

Senten, J.R. and Charlier, R.H., 1991. Heavy metals sediments pollution in estuarine and coastal waters: corrective measures for existing problems. International Journal of Environmental Studies, 37(1-2), 79-96.

Tsai, T.L.; Chang, K.C., and Huang, L.H., 2006. Body force effect on consolidation of porous elastic media due to pumping. Journal of the Chinese Institute of Engineers, 29(1), 75-82.

Zhang, H.J.; Jeng, D.S.; Seymour, B.R.; Barry, D.A., and Li, L., 2012. Solute transport in partially-saturated deformable porous media: Application to a landfill clay liner. Advances in Water Resources, $40,1-10$. 